\title{
Effect of low dose gamma radiation on electric conductivity of LDPE and PMMA polymers
}

\author{
N. Madania ${ }^{a}$ D. Sardari ${ }^{a^{*}}$, M. Hosntalab ${ }^{a}$ and P. Zobdeh
}

${ }^{a}$ Department of Medical Radiation Engineering, Science and Research Branch, Islamic Azad University, P.O. Box 14515-775, Tehran, Iran ${ }^{b}$ Department of Physics, Qom Branch, Islamic Azad University, Qom, Iran

\begin{tabular}{|c|c|}
\hline $\bar{A} \mathbf{R}$ & A B S T RACT \\
\hline Article history: & \multirow{11}{*}{$\begin{array}{l}\text { An experimental analysis of the effect of gamma and X-ray irradiation with dose rate } 0.25-6 \mathrm{mSv} / \mathrm{h} \\
\text { on low-density polyethylene (LDPE) and PMMA samples is presented. The focus of attention is } \\
\text { on their DC conductivity as a dielectric of a capacitor. This system is based on the discharge of a } \\
\text { capacitor by radioactive radiation through ionization of the dielectric consists of an inner electrode } \\
\text { of the capacitor. The experimental setup contains a special electronic circuit in which polymer } \\
\text { samples are placed as dielectric of parallel-plate capacitor which is connected to electrodes and a } \\
\text { high voltage power supply is in series with other components of the circuit. It is understood that } \\
\text { the resistance of polymers varies with the applied voltage and absorbed gamma ray dose from }{ }^{137} \mathrm{Cs} \\
\text { with } 0.661 \mathrm{MeV} \text { energy. The influences of this parameter on LDPE and PMMA electrical } \\
\text { properties as a result of polarization of dielectric are also presented. The experimental results show } \\
\text { elevation of LDPE and PMMA electric conduction properties as irradiation dose rate increases. } \\
\text { Indications of predominance of charge accumulation are also observed. }\end{array}$} \\
\hline & \\
\hline Aceppled 20 Aug & \\
\hline & \\
\hline $\begin{array}{l}28 \text { August } 2019 \\
\text { Keywords: }\end{array}$ & \\
\hline $\begin{array}{l}\text { neyworas. } \\
\text { Gamma irradiation }\end{array}$ & \\
\hline Polymers & \\
\hline Electrical properties & \\
\hline$L D P E$ & \\
\hline PMMA & \\
\hline & \\
\hline
\end{tabular}

(C) 2020 Growing Science Ltd. All rights reserved.

\section{Introduction}

The question of reliability of modern electronic devices in harsh radioactive environment is still a matter of concern in production of active and passive electrical components. Under the influence of high flux and /or high energy ionizing radiation irreversible changes of the constituting material characteristics might occur (Osmokrovic et al., 1998). Since five decades ago the understanding of the radiation effects on polymers began to attract attention of manufacturing companies. The irradiation of polymeric materials with X-and gamma ray photons as well as accelerated electrons and ions beams leads to undesirable deterioration in their electrical characteristics (Chmielewski, 2005). Although ionizing radiation effects on dielectric materials in passive components can be neglected, similar situation in active electric circuits may result in remarkable changes of their performance. The basic component in active electric circuits whose functioning is depending on dielectric materials is capacitors (Loncar et al., 1998). The Radiation Induced Conductivity (RIC) phenomenon in many kinds of polymers has been studies literature (Omar et al., 2013; Nouh \& Abdel-Naby, 2003; Upadhyay \& Reddy, 2017). It has been observed that these insulating materials exhibit complex non-linear conduction current (charge transport in dielectric) when used under high dc stress and the maximum voltage level of extruded HVDC cable

* Corresponding author.

E-mail addresses: sardari@srbiau.ac.ir (D. Sardari) 
systems could not be increased beyond a few hundred kilo volts. The conduction current is also considered responsible for the understood space charge accumulation, which has variations with respect to the local electric field within the material. It influences the breakdown capability of insulators due to distortion of the local electric field (Upadhyay and Reddy, 2017). Therefore, radiation changes the electrical properties of the material it penetrates. The degree of these changes provides information on the level of radiation received (Arshak, 2005).

It is well known that irradiation enhances the electrical conductivity in insulating polymers. This increase in conductivity attributes to the amplifications of conjugated structure, i.e. fairly enhanced electron freedom (Swu et al., 2013). Irregularities in the polymer chains may also give rise to a hopping mechanism which then increases the conductivity (Fares, 2011). In recent years, natural polymers are attracting renewed interest due to unique specifications such as inherent biocompatibility, biodegradability and easy availability (Chmielewski et al., 2005). Enhancement of performance of radiation sensors has been in focus of many research works through both the materials properties and manufacturing technologies. For this purpose, a deep understanding of physical properties of metal oxides and polymer materials under the influence of $\gamma$-radiation is considered to achieve effective design of novel dosimeters (Arshak et al., 2014). Irradiation modifies the physical properties of polymers because the radiation process directly provides the energy required for changes in electronic states of the matter. Huge amount of ionizing radiation impinging on a polymeric sample, causes irreversible changes in its macromolecular structure (Raghu et al., 2016). The physical principle of converting radiation dose to electric current or voltage at the output of dosimeter is very similar for all kinds of dosimeters. Minor details in construction of switches, connectors, capacitor, arrangement of the electrodes of the ionization chamber, and in the design of the measuring device might be different (Kowalski, 1962).

Gamma rays impinging on the polymer produce a change in the density of charge carriers, which alters its properties in measurable way. In the present work especially electrical conductivity of the polymer has been varied as function of gamma ray dose (Arshak et al., 2005). Such variations are strongly governed by the physics and chemistry of the absorbing materials; as well as the radiation energy and intensity. The radiation effects may cause occurrence of ionization or excitation of the electrons in atoms, rendering them free or loosely bonded to some trapping centers elsewhere in the sample (Zahran et al., 1993). In the present work we investigated enhanced electric conductivity in a polymer sample that is induced gamma ray. This is called radiation induced conductivity (RIC) (Paulmier et al., 2014). Radiation-induced conductivity (RIC) serves to remove the excess space charges appearing in the bulk of the polymer to the metalized layers on its sides (Tyutnev et al., 2001). Several physical effects on RIC and charge transport in polymers are however not taken into account, such as induced de-trapping or recombination, molecular mobility, polarization processes and the overall effect of electric field on charge carrier dissociation and charge mobility.

\section{Materials and Methods}

\subsection{Materials}

\subsubsection{Polymer samples}

The samples used in electrical conductivity measurements were low-density polyethylene (LDPE) and PMMA, two widely used and well-characterized semi-crystalline polymers, having the form of plates of $10 \times 10 \mathrm{~cm}^{2}$ and with thickness of $1 \mathrm{~mm}$, even though thicker samples up to $5 \mathrm{~mm}$ were examined as well. Samples were chemically cleaned with methanol before running the experiment. Other properties of polymers are represented by $\rho$ being its density, $\rho_{0}$ specific resistivity, $\mathrm{s}$ electrical conductivity and $\kappa$ dielectric constant (Table 1). Other parameters affecting RIC like material structure and state (composition, structure, crystallization) remained constant. 
Table 1. Properties of utilized polymeric samples

\begin{tabular}{ccccc}
\hline Material & $\rho\left(g / \mathrm{cm}^{3}\right)$ & $\rho_{0}(\Omega . c m)$ & $\mathrm{s}(\mathrm{S} / \mathrm{m})$ & $\kappa($ at $1 \mathrm{MHz})$ \\
\hline LDPE & $0.912-0.930$ & $16-18$ & & 2.25 \\
PMMA & 1.18 & $14-18$ & $1 \mathrm{E}-16$ & 3.6 \\
\hline
\end{tabular}

\subsubsection{Irradiation source}

The gamma irradiation process was carried out in the Nuclear Physics Laboratory of Islamic Azad University, Science and Research Branch which is equipped with a standard cylindrical Cs-137 source with activity of $0.2 \mathrm{mCi}$, manufactured by the Atomic Energy Authority of Iran. This source produces dose rate in the range $0.12-24.5 \mathrm{mSv} / \mathrm{h}$ depending on the source-detector distance usually applicable in the lab. All measurements were carried out while the sample was under irradiation. Values of DC conductivity were measured at room temperature. In our research, the radiation dose absorbed by the sample is low enough so that the samples do not undergo crosslink or chain scission leading to alterations in its macromolecular structure.

\subsection{Methods}

Resistivity of an insulator can be found using the thin film capacitor approximation (Frederickson \& Dennison, 2003). For highly resistive materials, measurements involve with extremely small currents and the presence of a polarization field within the sample can cause minor errors. Here the applied voltage was kept constant (Brunson \& Dennison, 2006). In experiment the setup is based on the discharge of a capacitor by gamma radiation through ionization of the dielectric and consists of two parallel plate electrodes as the capacitor and an electrical circuit completes the setup in which polymer samples are placed as dielectric of capacitor and parallel-plate capacitor is connected to electrodes of high-voltage power supply (Fig. 1). During irradiation all circuit components such as multi-meter or high voltage power supply were kept out of radiation field or shielded by proper layers of lead and radiation effects on them were considered negligible.

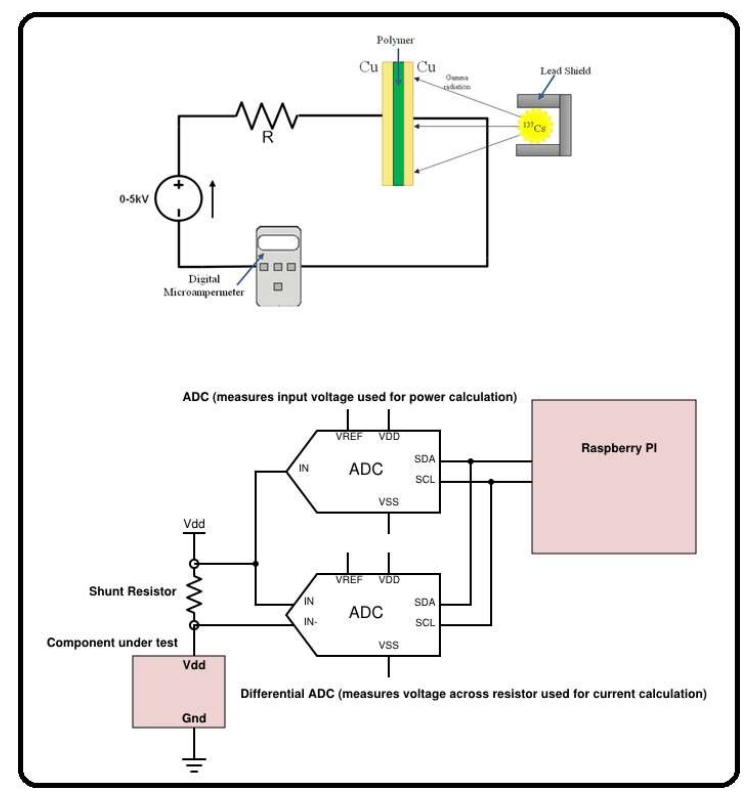

Fig. 1. Electric circuit setup for readout the dose rate. 


\subsubsection{Electrical Conductivity Measurements}

The measuring procedure was based on measurements of the DC conductivity for all irradiated and non-irradiated LDPE and PMMA samples while in use as dielectric of capacitors. The electrodes were made of $1 \mathrm{~mm}$ thick copper covering the two major surfaces of the samples. The current was measured using a digital electrometer (Type Escort 176) and DC voltage power supply (type LB 52237) in range of $0-5 \mathrm{kV}$ and therefore the applied electric field intensity was varied in $0-5 \mathrm{kV} / \mathrm{mm}$ range. A safety resistor of $100 \Omega$ was in series to the circuit in order to harness unusual surges of currents.

The "dark current" of the system (observed in absence of the external radiation source) is in order of few $\mu \mathrm{A}$ magnitude which is due to the leakage current in the measuring system. Before commencing the measurement, the capacitance is charged to a given voltage U. If the system is exposed to ionizing radiation, an electrical current then flows through the samples and diminishes the charge deposited in the capacitance by an amount proportional to the total radiation dose received in a given case.

\section{Results and discussion}

In authors' previous article, an analysis of conductive flow compared to the direct bias voltage applied in different doses for LDPE and PMMA samples with $1 \mathrm{~mm}$ thickness were discussed and the results are presented in Figs. $2 \mathrm{a}$ and $2 \mathrm{~b}$ which shows that according to the theory of conductivity, by applying a voltage of about $2.5-3 \mathrm{kV}$, the applied electric field is strong enough that it can overcome the load on the schottcky barrier and observing the conductive current, while dark current and conduction current are of the order of $\mu \mathrm{A}$. The results of conduction current before and during different radiation dose rates versus bias voltages are also depicted in this Figure for each dose rate.

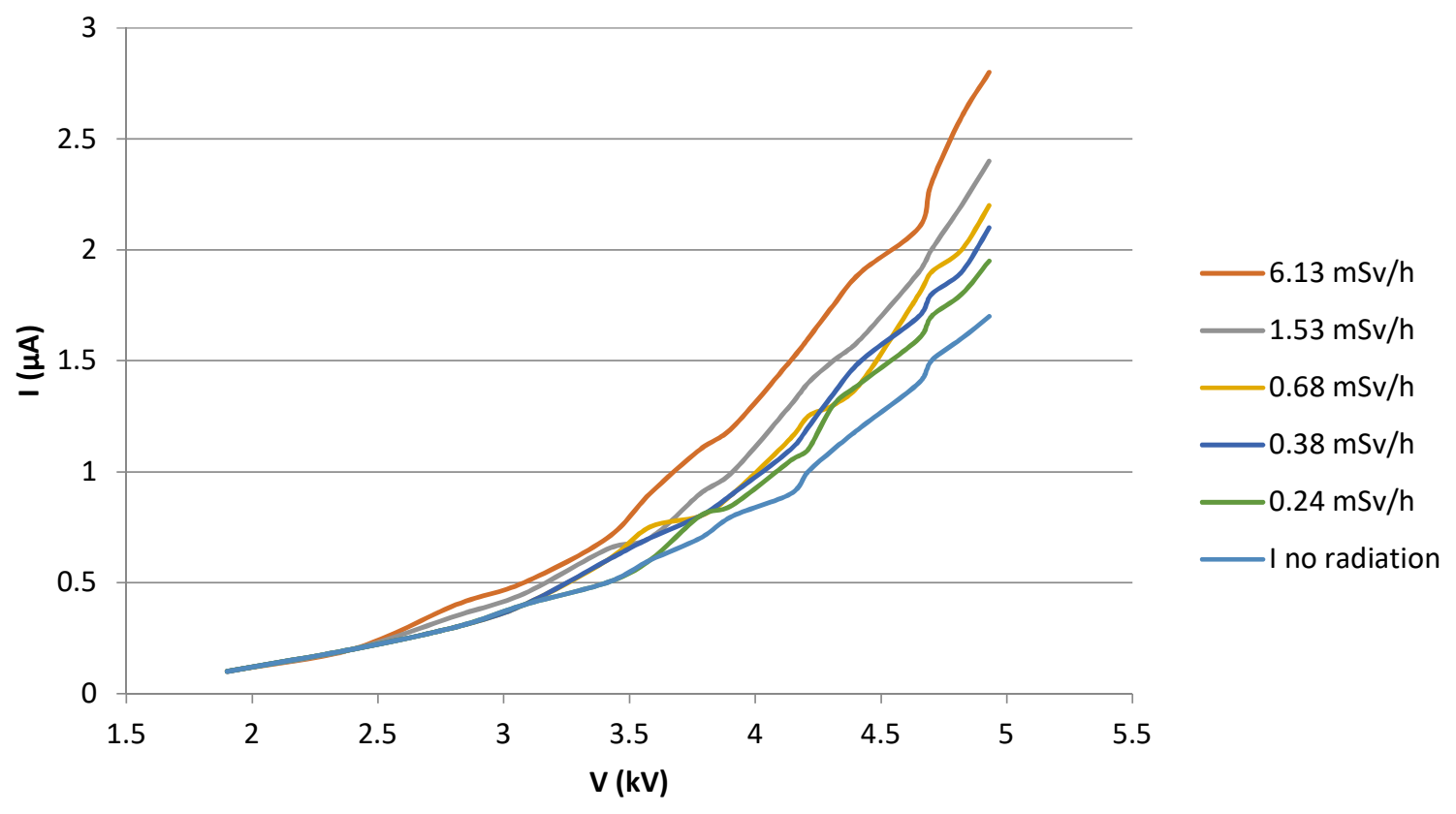




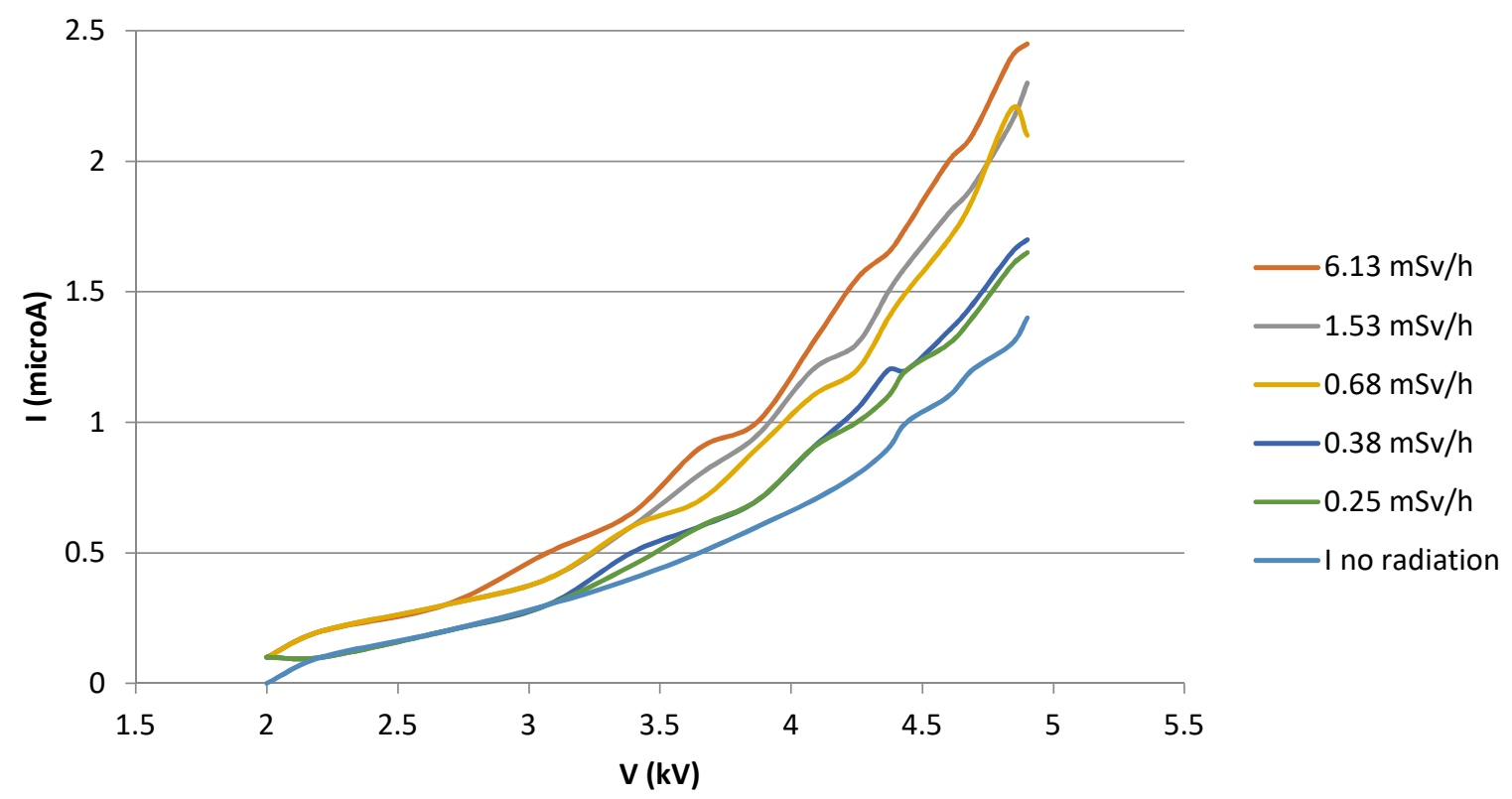

(b)

Fig. 2. Conduction current before and during different dose rates for $1 \mathrm{~mm}$ LDPE sample (a) and $1 \mathrm{~mm}$ PMMA sample (b) (Madani et al., 2018)

I-V measurements of samples in which I is conduction current indicates that the response is almost linearly varying against the absorbed dose rate at $4.4 \mathrm{kV}$ bias voltage. On the other hand, the increase in the current flow associated with the radiation dose increases up to a certain level, and then the conduction current reaches saturation. The increase in voltage across the capacitor does not seem to result in release of more charge carrier (no occurrence of avalanche). In other words, with increase in the number of charge carriers, the sample's conductivity only went up to the saturation region. The saturation of electric current passing through the polymer sample is caused by little amount of recombination of charge carriers at higher voltages. Thus all the released charges are absorbed by the capacitor plates. The number of electrons and ions produced due to exposure in time unit in the dielectric material depends on the intensity of the gamma ray beam, and if this factor is exacerbated, the amount of electrons and ions produced in the unit time increases and vice versa.

Before the saturation point, due to the sufficient opportunity for ions and electrons, re-combination leads to their neutralization. Therefore, the rate of current flow through the sample is reduced. At the point of saturation, the electric current reaches its highest value but then, due to the fact that all the electrons and ions are of a high velocity and immediately reach the anode and the cathode, the flow rate remains constant. Variation in resistivity of samples during irradiation is presented in Fig. 3. In both of samples resistivity is decreased by increasing the dose rate of gamma rays while applying $3 \mathrm{kV}$ to circuit. By ascending electric field caused by the high voltage, variations in resistivity became more observable especially for LDPE sample and in $4.7 \mathrm{kV}$. The initial currents results from shallow traps, which, as seen in Fig. 3, have no contribution in conduction flow. But when the electrons are released from deeper traps, the current is generated that, if the density of deep traps in a particular energy is very high, the current at a certain voltage suddenly increases. 


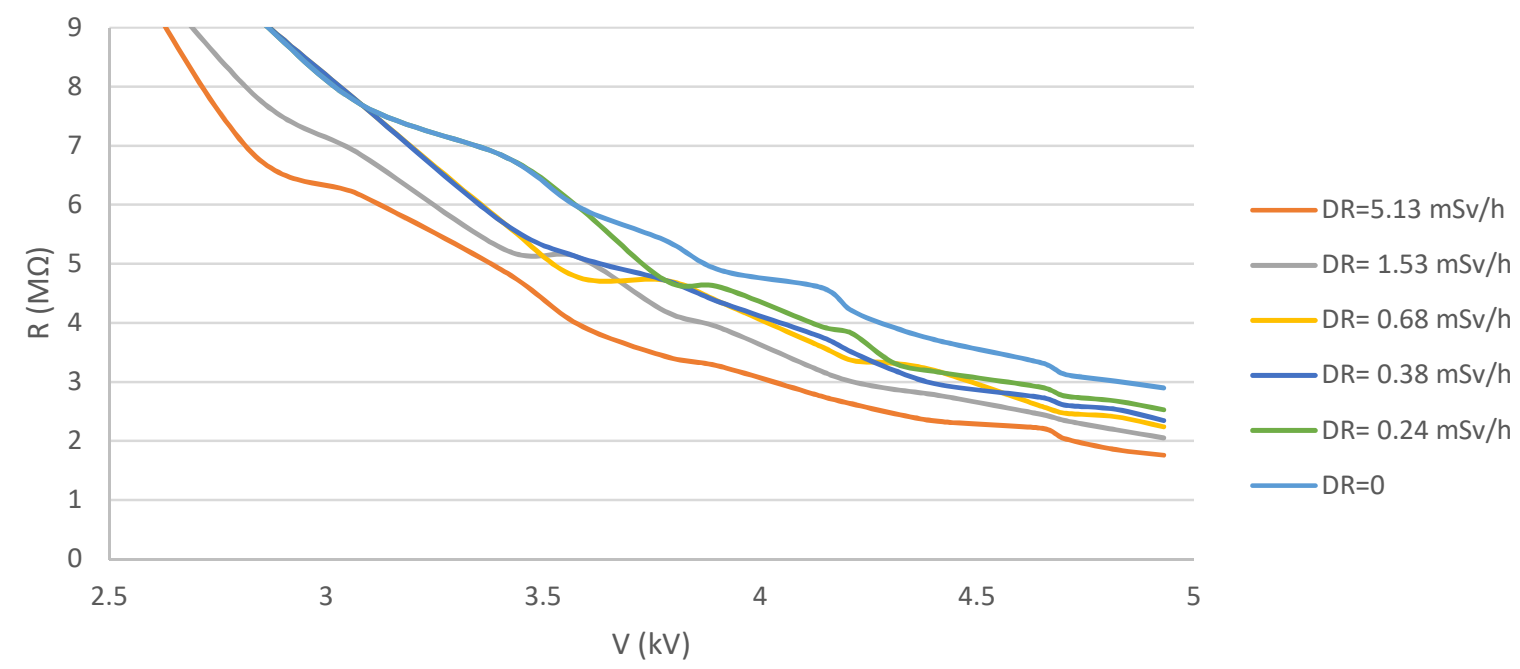

(a)

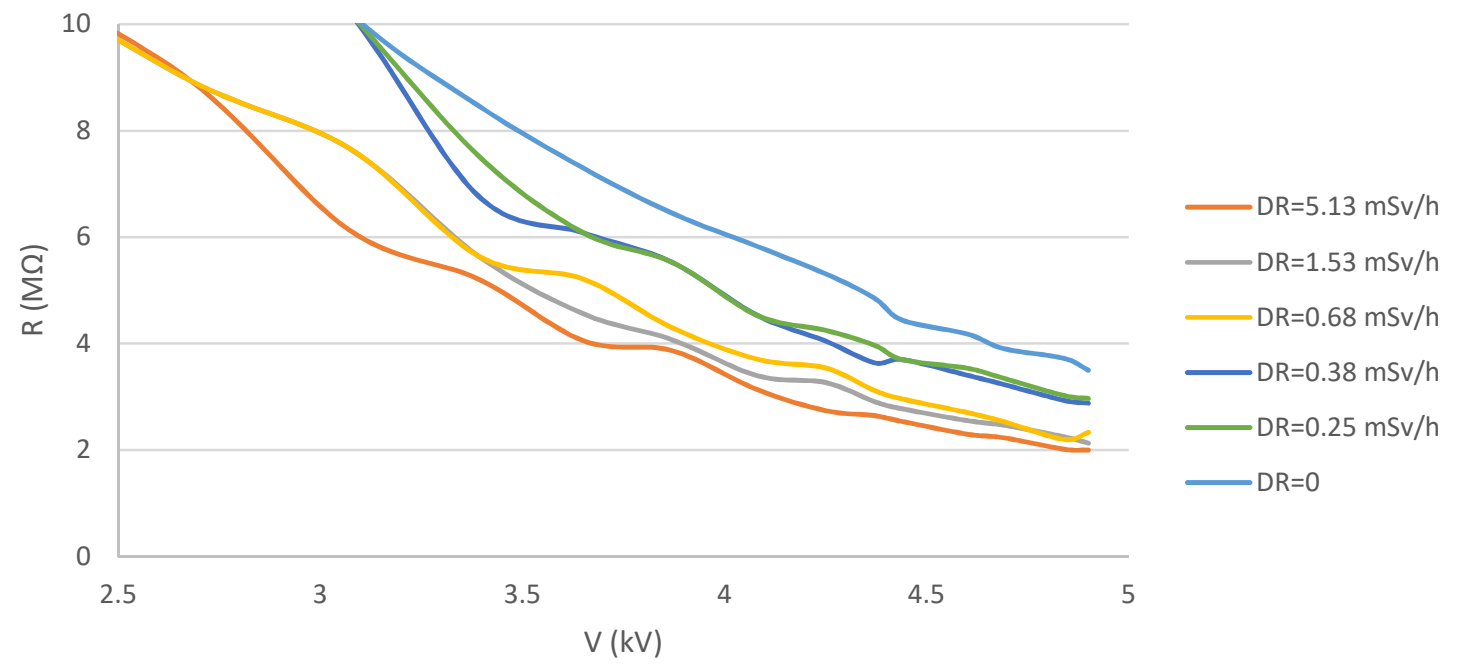

(b)

Fig. 3. Change in the value of resistivity with voltage and radiation dose rate for (a) $1 \mathrm{~mm}$ LDPE and (b) 1 mm PMMA

An inevitable property of insulation is its parasitic leakage resistance R. Its product with the capacitance value $\mathrm{C}$ gives a time constant $\mathrm{RC}$, which depends on the properties of the insulator material and is little affected by the construction. Due to high resistivity in the most modern insulators made of polymeric synthetics it is possible to obtain time constants of the order of years. In our practice the polymer is thin and hence the resistivity is low enough to produce time constant of microseconds suitable for a radiation detector. The above-mentioned leakage resistance $\mathrm{R}$ causes capacitance discharge happen spontaneously even when no irradiation is present. Further sources of error are provided by inaccurate setting of the charging voltage $U$ and by changes in the dosimeter voltage due to polarization effects such as can be perceived in highly insulated capacitor foils. By considering $\mathrm{C}$ as capacitance, $\mathrm{k}$, dielectric coefficient of the material, A, the cross section of the capacitor plates and $\mathrm{d}$ as the distance between the two capacitor plates, since $\mathrm{k}_{\mathrm{PE}}=2.25$ and $\mathrm{k}_{\mathrm{PMMA}}=3.6$ and $\mathrm{d}=1 \mathrm{~mm}$ and $\mathrm{A}=100 \mathrm{~cm}^{2}$, the capacitance of the parallel plate capacitor introduced in this article can be calculated. If $\mathrm{d}=1 \mathrm{~mm}$ :

$$
C=k \varepsilon_{0} \frac{A}{d}
$$




$$
\begin{aligned}
& C_{P E}=2.25 \times 8.85 \times 10^{-12} \times \frac{10^{-2}}{10^{-3}}=199 \mathrm{pF} \\
& C_{P M M A}=3.6 \times 8.85 \times 10^{-12} \times \frac{10^{-2}}{10^{-3}}=318 \mathrm{pF}
\end{aligned}
$$

By bearing in mind the resistivity measurements presented in Fig. 3, time constant RC can be calculated. Since resistivity of both kind of samples has been in order of $M \Omega$ and capacities are in order of $\mathrm{pF}$, so $\mathrm{RC}$ would be in order of $\mu \mathrm{s}$. It is concluded that time constant is proper to make the device useable as a photon detector (Brunson \& Dennison, 2006). In these experiments, we did not reach the electrical breakdown of the samples. In the case of conductive filler particles, the conductivity in the system should increase significantly after reaching this position, which is called the threshold of penetration (Arshak et al., 2005). The DC electrical conductivity, s, was determined from the relation (Nouh \& Abdel-Naby, 2003).

$$
s=\frac{I d}{V A},
$$

thus,

$$
\Delta s=\frac{\Delta I \cdot d}{V A},
$$

where $\mathrm{d}$ is the thickness of the examined sample in $\mathrm{cm}, \mathrm{A}$, cross-sectional area of the sample in $\mathrm{cm}^{2}, \mathrm{~V}$, applied voltage in volts, $I$, current in Ampere and $\Delta s$, variation in electrical conductivity. Since $A=100$ $\mathrm{cm}^{2}$ and $\mathrm{d}=0.1 \mathrm{~cm}$, so for $\mathrm{V}=4.5 \mathrm{kV}$, variation in electrical conductivity, $\Delta \mathrm{s}$, can be as seen in Table 2 . Fig. 4 also presents the variation of conductivity versus dose rate at $4.5 \mathrm{kV}$ for both investigated samples with $1 \mathrm{~mm}$ thickness.

Table 2. Variation in electrical conductivity versus dose rate for LDPE and PMMA

\begin{tabular}{ccccc}
\hline & \multicolumn{2}{c}{ LDPE } & PMMA \\
\cline { 2 - 5 } Dose rate $(\mu \mathrm{Sv} / \mathrm{h})$ & $\Delta \mathrm{I}(\mu \mathrm{A})$ & $\begin{array}{c}\text { Variation in Electrical } \\
\text { Conductivity }(\mathrm{S} / \mathrm{m})\end{array}$ & $\Delta \mathrm{I}(\mu \mathrm{A})$ & $\begin{array}{c}\text { Variation in Electrical } \\
\text { Conductivity }(\mathrm{S} / \mathrm{m})\end{array}$ \\
\hline 6.138 & 0.7 & $15.6 \mathrm{E}-12$ & 0.9 & $20.0 \mathrm{E}-12$ \\
2.728 & 0.5 & $11.1 \mathrm{E}-12$ & 0.7 & $15.6 \mathrm{E}-12$ \\
1.534 & 0.4 & $8.9 \mathrm{E}-12$ & 0.5 & $11.1 \mathrm{E}-12$ \\
0.98 & 0.3 & $6.7 \mathrm{E}-12$ & 0.45 & $10.0 \mathrm{E}-12$ \\
0.683 & 0.25 & $5.6 \mathrm{E}-12$ & 0.35 & $7.8 \mathrm{E}-12$ \\
0.501 & 0.2 & $4.4 \mathrm{E}-12$ & 0.25 & $5.6 \mathrm{E}-12$ \\
0.38 & 0.2 & $4.4 \mathrm{E}-12$ & 0.2 & $4.4 \mathrm{E}-12$ \\
\hline
\end{tabular}

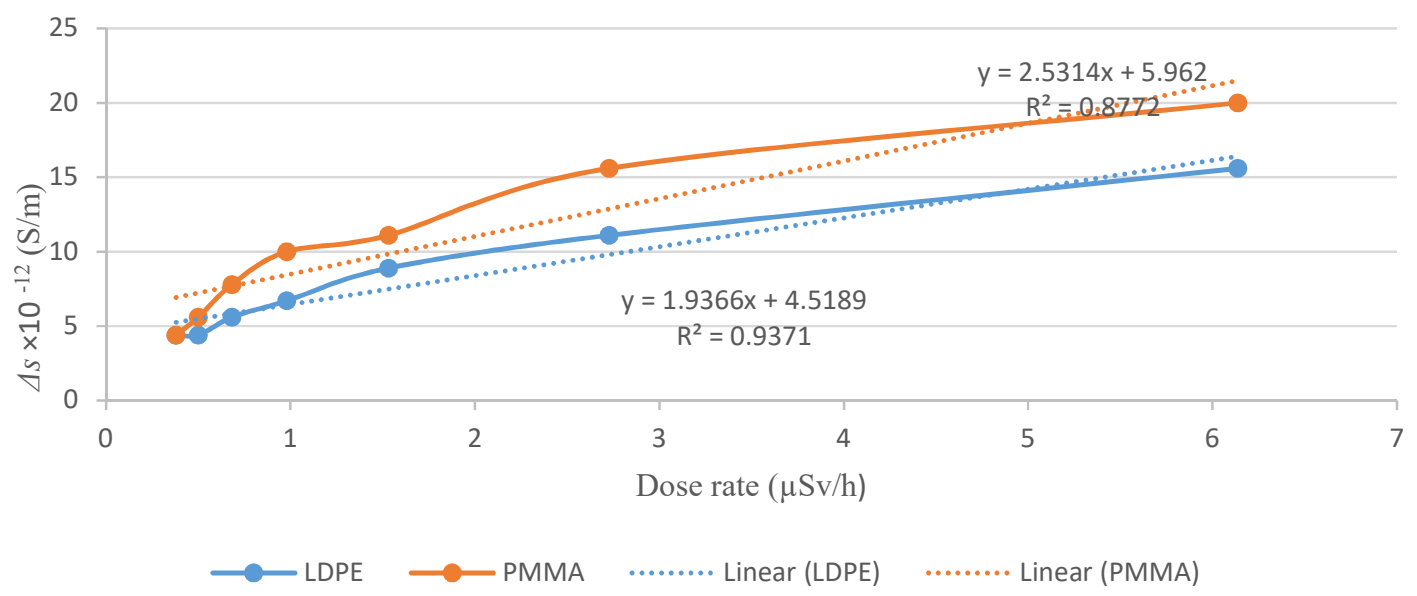

Fig. 4. Variation of conductivity versus dose rate at $4.5 \mathrm{kV}$ for LDPE and PMMA samples with $1 \mathrm{~mm}$ thickness 


\section{Conclusion}

The results of examination of solid dielectrics in a radioactive environment due to variation in their electrical resistivity were presented. Analysis of the changes in the electrical properties of the LDPE and PMMA samples undergone to gamma irradiation shows that (i) resistivity of both samples is decreased as irradiation dose rate increased, indicating the predominance of charge accumulation in the polymer with the implication of this effect being more pronounced at higher voltages specially for PMMA sample. This case is clearly observed in Fig. 3. These data serve to confirm the results reported in the literature (Upadhyay \& Reddy, 2017; Frederickson \& Dennison, 2003). (ii) By ascending electric field intensity caused by high voltage, differences in resistivity became more apparent especially for LDPE samples in the applied voltage of $4.7 \mathrm{kV}$, which is close to recommended voltage value introduced in our previous work (Madani et al., 2018). (iii) Electrical conductivity values for both of the irradiated samples were higher than those for the non-irradiated one, although tendencies were not well identified. (iv) From the linear regression fits, increment in variation of conductivity versus dose rate at $4.5 \mathrm{kV}$ for LDPE and PMMA samples with $1 \mathrm{~mm}$ thickness is almost linear in both samples although this linearity in PMMA looks less than LDPE but intensification in conductivity of former is more than LDPE. (v) The electrical conductivity of polymers is very low and mainly spanned in the range of $10^{-16}-10^{-12} \mathrm{~S} / \mathrm{m}$ (Callister Jr \& Rethwisch, 2012), an analysis of the above-mentioned data shows that for both of our samples, $\Delta \mathrm{s}$ is in order of $10^{-12} \mathrm{~S} / \mathrm{m}$, thus it satisfies measurements reported in the literatures.

It is important to mention that the experimental framework used in the present research was designed to allow a comparative study of the electrical properties of non-irradiated and irradiated samples of a specific LDPE and PMMA materials. Thus, the validity of the data and conclusions gained are limited by the assumptions and material used. In order to produce more general data, it is desirable to make use of additional complementary tests to better characterize the variations in the microstructure of the material due to the application of gamma radiation.

Considering the experimental data from a comparative perspective, the results show an improvement in LDPE and PMMA electrical strength properties as the radiation dose increases. These results indicate that sample thickness could be a very important parameter for the design of an irradiation test and should represent the real dimensions of the polymeric component to be submitted to radiation.

Experimental analysis of the effect of dose rate parameter during gamma irradiation of low-density polyethylene (LDPE) and PMMA samples and considerations concerning the influence of this parameter on LDPE and PMMA electrical properties as a result of polarization of dielectric presented showed an improvement of LDPE and PMMA conductional properties as dose rate increases and causes changes in resistance parameter when radiation is applied, indicating the predominance overcoming charge accumulation.

The basic idea of measuring the electric current emanated from gamma ray interaction in material is applicable in manufacturing and performance of radiation dosimeters. Besides gamma and X-ray, planeparallel plate dosimeters are envisaged for charged particle dosimetry (Scarlat et al., 2015; Scarlet et al., 2016). In this case, the damages in molecular structure of polymer caused by massive charged particles would be interesting area of further work.

\section{Acknowledgement}

The authors would like to thank Nuclear Physics Laboratory, Science and Research Branch, Islamic Azad University staff and Nuclear Physics Laboratory of Kharazmi University at Karaj. 


\section{References}

Arshak, K., Arshak, A., Zleetni, S., \& Korostynska, O. (2014). Thin and thick films of metal oxides and metal phthalocyanines as gamma radiation dosimeters. IEEE Transactions on Nuclear Science, 51, 2250-2255.

Arshak, K., Morris, D., Kaneswaran, K., Korostynska, O., \& Arshak, A. (2005). Portable Real-Time Gamma Radiation Dosimetry System Using $\mathrm{MgO}$ and $\mathrm{CeO} 2$ Thick Film Capacitors. In International Conference on Sensing Technology, Palmerston North, New Zealand.

Brunson, J., \& Dennison, J. R. (2006). E-Field Dependent Conduction in Low-Density Polyethylene.

Callister Jr, W. D., \& Rethwisch, D. G. (2012). Fundamentals of materials science and engineering: an integrated approach. John Wiley \& Sons.

Chmielewski, A. G. (2005, August). New trends in radiation processing of polymers. In Proceedings of Interntional Nuclear Atlantic Conference (INAC 2005).

Chmielewski, A. G., Haji-Saeid, M., \& Ahmed, S. (2005). Progress in radiation processing of polymers. Nuclear Instruments and Methods in Physics Research Section B: Beam Interactions with Materials and Atoms, 236(1-4), 44-54.

Fares, S. (2011). Frequency dependence of the electrical conductivity and dielectric constants of polycarbonate (Makrofol-E) film under the effects of $\gamma$-radiation. Natural Science, 3(12), 1034.

Frederickson, A. R., \& Dennison, J. R. (2003). Measurement of conductivity and charge storage in insulators related to spacecraft charging. IEEE Transactions on Nuclear Science, 50(6), 2284-2291.

Loncar, B., Novakovic, D., \& Osmokrovic, P. (1998, June). Radioactive resistance of solid dielectrics. In 12th International Conference on High-Power Particle Beams. BEAMS'98. Proceedings (Cat. No. 98EX103) (Vol. 1, pp. 293-296). IEEE.

Madani, N., Sardari, D., Hosntalab, M., \& Zobdeh, P. (2018). Real time dose rate meter for gamma radiation using LDPE and PMMA in presence of $1-5 \mathrm{kV} / \mathrm{mm}$ electric field. Radiation Physics and Chemistry, 151, 164-168.

Nouh, S. A., \& Abdel-Naby, A. S. (2003). Investigation of the effect of gamma rays on electrical properties of chlorinated poly (vinyl chloride). Radiation effects and defects in solids, 158(8), 553560.

Omar, A., Baraka, A., Zaki, A. H., \& Sharshar, K. A. (2013). Gamma radiation effect on the electrical properties of PANI film. In Applied Mechanics and Materials (Vol. 241, pp. 828-832). Trans Tech Publications.

Osmokrovic, P., Stojanovic, M., Loncar, B., Kartalovic, N., \& Krivokapic, I. (1998). Radioactive resistance of elements for over-voltage protection of low-voltage systems. Nuclear Instruments and Methods in Physics Research Section B: Beam Interactions with Materials and Atoms, 140(1-2), 143151.

Paulmier, T., Dirassen, B., Arnaout, M., Payan, D., \& Balcon, N. (2015). Radiation-induced conductivity of space used polymers under high energy electron irradiation. IEEE Transactions on Plasma Science, 43(9), 2907-2914.

Raghu, S., Archana, K., Sharanappa, C., Ganesh, S., \& Devendrappa, H. (2016). Electron beam and gamma ray irradiated polymer electrolyte films: Dielectric properties. Journal of Radiation Research and Applied Sciences, 9(2), 117-124.

Scarlat, F., Scarisoreanu, A., Badita, E., Vancea, C., Calina, I. I., Scarlat, F., \& Verga, N. (2015). Ionization chamber dosimetry for conventional and laser-driven clinical hadron beams. Journal of Biosciences and Medicines, 3(04), 8-17.

Scarlet, F., Verga, N., Scarisoreanu, A., Badita, E., Demeter, M., Stancu, E., Vancea, C., \& Scarlet, FL. (2016). Absorbed dose determination in conventional and Laser-driven hadron clinical beams using electrical charge measurements. Romanian Reports in Physics 68 (1), 210-219.

Swu, T., Pongener, C. A., Sinha, D., \& Sen Sarma, N. L. (2013). Effect of gamma radiation on dielectric properties of polyacetate polymer. Pelagia Res. Lib, 4(3), 132-136. 
Tyutnev, A. P., Kundina, Y. F., Saenko, V. S., Doronin, A. N., \& Pozhidaev, E. D. (2001). Radiationinduced conductivity of poly (ethylene terephthalate): Theoretical model and its applications. High Performance Polymers, 13(3), S493-S504.

Upadhyay, A. K., \& Reddy, C. C. (2017). On the mechanism of charge transport in low density polyethylene. Journal of Applied Physics, 122(6), 064105.

Zahran, A. R. R., Kandeil, A. Y., Higazy, A. A., \& Kassem, M. E. (1993). Ultrasonic and thermal properties of $\gamma$-irradiated low-density polyethylene. Journal of applied polymer science, 49(7), 12911297.

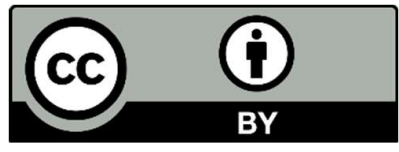

(C) 2020 by the authors; licensee Growing Science, Canada. This is an open access article distributed under the terms and conditions of the Creative Commons Attribution (CC-BY) license (http://creativecommons.org/licenses/by/4.0/). 